Article

\title{
Socioeconomic Reinvention and Expanding Engagement with Climate Change Policy in American Rust Belt Cities
}

\author{
Scott E. Kalafatis \\ Falk School of Sustainability and Environment, Chatham University, Pittsburgh, PA 15232, USA; \\ S.Kalafatis@chatham.edu
}

Received: 16 October 2020; Accepted: 3 December 2020; Published: 7 December 2020

\begin{abstract}
Despite an appreciation for the role of cities in addressing global climate change, more studies are needed that explore how climate change policies relate to cities' everyday governing concerns. Such insights are critical for understanding how climate change policy will expand, play out, and evolve as it moves from experimental efforts in particularly innovative cities to the majority of cities. This study addresses these needs using 32 interviews and over 200 survey responses from smaller cities (populations under 100,000) in the American rust belt. In the interviews comparing cities' financial concerns, economic development considerations, and how other cities influence them, a distinctive mindset amongst cities highly engaged with climate change emerged. Highly engaged cities were those pursuing socioeconomic reinvention, informed by efforts to identify and apply policy ideas from a wide range of other cities across the United States and internationally. Results of the regression analyses supported the notion that financial concerns, economic development considerations, and the influence of other cities shape decisions about climate change policy in these cities. However, they also highlighted the complexity of these issues and that the role these factors had in shaping climate change policy will likely continue to evolve as these policies continue to diffuse to more places.
\end{abstract}

Keywords: urban; municipal; diffusion; innovation; city networks; co-benefits

\section{Introduction}

Cities are currently critical niches for the development of climate change policies [1,2]. However, the continued development of social scientific theories of local climate change politics and governance requires cultivating a deeper understanding of the local political and governing processes that drive the emergence of these efforts [3]. Many studies have identified factors associated with local governments pursuing climate change mitigation and adaptation [4-6]. This work shed some light on what conditions generally make the pursuit of these efforts more likely to emerge in the first place, expand, and be sustained. But the level of insight it has been able to provide related to the specificities of how climate change governance plays out in individual contexts and the extent to which necessary deeper social changes are actually occurring in these contexts has been limited [7]. More attention is needed regarding how climate change policy efforts relate to local governments' mundane, everyday activities to gain a better perspective on how climate change policy relates to cultural and socioeconomic change [7].

Analysis of the ideas and ways of thinking, i.e., the governmental rationalities or governmentalities, that underlie the processes of climate change governance can contribute to the development of a more robust understanding [8,9]. When successfully coupled with explanatory theories of behavior, analysis of governmentalities can illustrate why patterns emerge in climate change policy. Understanding how these logics provide traction for climate change policy in communities that are not immediately 
recognizable as global leaders is particularly critical for understanding how these efforts can be made relevant and how they will play out in the vast majority of cities in the world that are not viewed as global exemplars [10-13]. Such cities' considerations are currently under-researched, limiting understanding of how climate change policies will ultimately scale up through diffusion beyond better-known global frontrunners [10,14].

This paper explores how the logic of political economic rationalism shapes the pursuit of climate change policy. Specifically, it examines how financial pressures, economic development considerations, and the influence of other cities affect whether or not cities embrace climate change as an issue that impacts their decision making. Attention was focused on cities in the eight U.S. states surrounding the Great Lakes, i.e., Illinois, Indiana, Michigan, Minnesota, New York, Ohio, Pennsylvania, and Wisconsin. This area is associated with the U.S. "rust belt" whose formal manufacturing base has shrunk dramatically since the mid-20th century, resulting in cultural disruptions and economic redevelopment pressure $[15,16]$. Climate change is expected to make the region warmer, shift rain and snow patterns, and to increase exposure to more frequent and severe extreme events $[17,18]$. The region will likely experience threats related to water quality, tourism revenue losses (especially winter activities), uncertainty about future Great Lake water levels, and advancing invasive species destroying fragile native ecosystems [19]. Nevertheless, the region as whole lacks a clear, distinctive, and overwhelming climate change-based threat such as sea-level rise or glacial retreat, meaning that responses to climate change in the Great Lakes region might be relatively generally applicable to other areas. At the same time, this region's experience of a slowly developing, widespread economic crisis driven by global factors makes it a particularly fertile area for exploring cities' strategic responses to global change. The focus was on smaller cities in this region, those with a population between 5000 and 100,000 people, to bring attention to the common, everyday experience of pursuing climate change policy in this region. Much of the attention surrounding urban climate change policy in this region has focused on the region's largest cities such as Chicago and Minneapolis, but $98 \%$ of the cities across these eight states have populations of less than 100,000.

The next section provides background on the perceived political economic rationality of cities that is the basis for the assumptions used in the analysis about the impact of financial concerns, economic development considerations, and the influence of other cities on engagement with climate change policy. In Section 3, further light is shed on this topic by describing the methods and results related to 32 interviews conducted across 15 cities that were used to compare the political economic rationalities of cities that were highly engaged with climate change policy and those that were not pursuing climate change policy at all. In Section 4, building off of these observations and survey responses from over 200 cities, logistic regression analyses are performed to assess the association of factors related to city finances, economic development, and the influence of other cities with whether a city is highly engaged with climate change or not engaged at all. These results serve to examine how broadly applicable the findings from the interviews are in the region and how predictive certain factors are of high engagement with climate change policy. A discussion of the implications of these results follows in Section 5 before the conclusions in Section 6.

\section{The Political Economy of City Policy Decisions}

Understanding governance as an activity that emerges from historical, technological, and institutional conditions, i.e., as a product of a particular governmentality, provides a foundation for identifying the underlying principles that give rise to observable decision making and how these principles vary $[8,20]$. However, governmentality's flexibility, as a diagnostic tool, undermines its ability to act as a stand-alone approach for predicting and explaining policy behavior, as it offers a strategy for analysis but not its own set of testable causal theories about social change [20] (p. 2). Therefore, identifying a particular governmentality at play is required for a fuller account of urban climate change politics that offers explanatory frameworks and testable theories about the forces underlying action. 
For decades, a rationalist approach has been commonly used for understanding city policy decisions. Cities are assumed to use the provision of public services such as roads, water, sewers, and parks as a currency for competing with other cities for desired residents and investment [21,22]. Providing these services requires raising the necessary funds through taxes and service fees which might make living or investing in the community less attractive. Cities act strategically to meet their residents' demands for public services as efficiently as possible, thereby supplying desirable services and amenities at the lowest possible cost [23]. This "fiscal imperative" [24] leads cities to prioritize economic development over other concerns because it is a relatively uncontroversial way to ensure quality of life improvements [25]. Economic development generates additional revenue and investment for a city, which allows the city to invest in public services that attract and retain wealthy residents who might have relatively low service demands and be able to provide further contributions to city revenue [25].

These predictions about the influence of financial and economic development considerations on city policy decisions have been tested and debated extensively, especially in the USA. In the USA, many residents have attempted to live in places that reflect their service demands [26-28], a trend that has been influential enough to have factored into major public policy challenges such as spatial inequality, white flight, and de facto segregation [29]. Cities risk losing residents and investment if they are relatively inefficient and unresponsive [30,31]. This is especially the case if they fail to meet the needs of the particularly well-informed subset of wealthy individuals who may ultimately shape cities' considerations about providing public services [32]. Cities also competitively respond to the policy actions of other surrounding cities and experience greater competition when they share the same metropolitan region with many other cities [23,33].

While there is evidence that the political economy of city policy decisions is influenced by considerations about fiscal pragmatism and economic development, recently, there has been more attention given to cities' efforts to attract desired residents and investment through tailoring their reputations [34,35]. In a globalized economy featuring advanced telecommunications, urban development is no longer centered on developing and exchanging goods, but on developing and exchanging knowledge and innovation as well $[36,37]$. Many cities have responded by focusing on marketing themselves; oftentimes, as places with cultural, technological, and knowledge resources that might attract the increasingly mobile circulation of global capital and residents [38,39]. City brand development is a dialogue that continuously redefines a place's collective identity [35]. To be successful, this identity dialogue must balance internal and external perceptions with residents' perceptions of their culture, leave an impression on outsiders, and feature self-reflection about how outsiders' perceptions can inform a brand that effectively mirrors expectations [35]. Therefore, maintaining a city's reputation is a dynamic process that constantly evolves based on how a city engages with the influence of other places [35].

Researchers have identified connections between the emergence and development of climate change policy with cities' financial concerns, economic development, and efforts to establish and maintain a reputation relative to other cities. The ability to reframe climate change policy in a manner that strategically bundles it with other prevailing municipal concerns has been a significant factor behind the success of these policies [40,41]. Cities that have successfully pursued climate change policies have often done so as a means of reducing spending or meeting economic development goals. Synergies between climate change policies and these other interests have led them to view climate change actions as a "co-benefit" [42] or a "triple-win" that simultaneously allows the city to address mitigation, adaptation, and development $[43,44]$. In particular, there is evidence that cities overlap economic development considerations with their mitigation and adaptation efforts [45] and that economic development and financial considerations factor into their pursuit of climate change policy [46]. Tying together climate goals with financial or economic development goals or bringing economic development interests into the pursuit of climate change has also been used as a strategy to expand coalitions supporting climate change policies and to sustain interest over time [47-50]. Previous 
studies have also found evidence that changes in a city's efforts related to economic development can provide opportunities for the pursuit of climate chance policy interventions [46,48-50].

There is also evidence that some cities' climate change efforts are being influenced by what is going on in other cities. On the one hand, the emergence of policy entrepreneurship associated with climate change may spread amongst cities clustered together in the same metropolitan areas [51]. On the other hand, competition between cities clustered within larger metropolitan areas might present greater collective action challenges as smaller cities can "free ride" off of the actions of the larger cities present [52]. This might particularly affect the interest that small cities in metropolitan areas have to pursue climate change mitigation [46,53]. Studies have also found that practitioners have been framing climate change policies in ways that align with the reputation of being a progressive, competitive city. Climate change has offered an opportunity for at least some cities to strategically differentiate themselves as leaders on the world stage [54-57].

\section{Interviews}

\subsection{Survey Determining City Engagement}

The present study attempts to explore, in more depth, the relationships among financial concerns, economic development considerations, and the influence of other cities. However, first, an understanding of the influence of climate change on city policy making was needed. In the spring/summer of 2015, a survey was sent to staff members in 803 cities across the eight Great Lakes states. This survey population represented every city in these states with a population between 5000 and 500,000, which the researcher did not have a pre-existing relationship with and that had functioning email addresses to contact. The survey included sixteen different policy actions covering seven areas of policy making (e.g., land use and transportation) that the city could be undertaking. The list of these actions is included in Appendix A (also see [45] for more information). For each action, the respondent first answered whether or not the city had "taken or been involved in" each of these actions in the last five years and whether or not climate change mitigation or climate change adaptation had influenced these actions. There were 281 completed responses collected (response rate of 35\%).

\subsection{City Selection for Interviews}

Following the completion of the survey, cities were selected for more in-depth interviews about the connections between climate change policy and their considerations about economic development, financial concerns, and the influence of other cities. To help highlight distinctions among cities most and least engaged with climate change, cities that were highly engaged with climate change and those who had reported that climate change did not influence their policy actions at all were both chosen. Cities that had undertaken six or more policies influenced by climate change mitigation or adaptation were considered to be "highly engaged" cities because this put them in the 75th percentile of those cities surveyed. Table 1 provides a summary of the cities interviewed, the state they are in, the number of policy actions that they had reported were influenced by climate change in the survey (CC), and the number of interviews (\# Inter.) that were completed for each. To make sure that insight was being gained into experiences across a wide range of political economic contexts, cities were also selected that varied along many other factors. The first was the unemployment rate which was divided between those cities that were high amongst those analyzed in the study population (the 75th percentile or higher) or low (the 25th percentile or lower). Studies of policy innovation and adoption in local governments have used unemployment as an indicator of local socioeconomic deprivation [58-60], which can shape how authorities search for strategies to match the complexity of their environment and more effectively address the needs of their citizens [58]. Similarly, cities were selected with a range of median household income as well. The third was whether or not a city was in one of the large metropolitan areas in the region, which other studies have found might affect cities' considerations about undertaking climate change policy actions and how other cities influence 
them $[46,51,53]$. The political partisanship of the voting population was also varied based on the share of the vote Barack Obama (D) received relative to Mitt Romney (R) in city precincts in the 2012 Presidential Election because climate change is still a highly politicized issue in the USA [61]. In Table 1 below, partisanship differences amongst constituents are represented by subtracting the share of the vote candidate Romney received from the share of the vote Obama received (Partisan.)-therefore, the higher the number, the more the city has a Democratic-leaning voting population. Finally, to the extent possible, cities were selected from across the eight states. This selection approach resulted in seven cities that were highly engaged with climate change, and the interview responses from these cities could be compared to eight cities that were taking no actions influenced by climate change.

Table 1. Summary of cities interviewed.

\begin{tabular}{ccccccccc}
\hline City Name & State & CC & \# Inter. & Pop. & Income & Unemp. & Metro & Partisan. \\
\hline \multicolumn{7}{c}{ Cities Highly Engaged with Climate Change } \\
\hline Crystal & MN & 9 & 2 & 22,151 & 60,234 & Low & X & 23.00 \\
Edina & MN & 14 & 3 & 47,491 & 84,349 & Low & X & 6.72 \\
Harper Woods & MI & 6 & 3 & 14,236 & 44,778 & High & X & 56.49 \\
Ithaca & NY & 10 & 3 & 30,014 & 28,760 & Low & 72.54 \\
Ludington & MI & 8 & 2 & 8076 & 32,010 & High & & -2.84 \\
McHenry & IL & 7 & 2 & 26,992 & 66,297 & High & X & -6.34 \\
Monmouth & IL & 7 & 2 & 9444 & 33,842 & High & & 5.80 \\
\hline & & Cities Not Engaging with Climate Change at All & & \\
\hline Bryan & OH & 0 & 1 & 8545 & 37,171 & High & & -3.65 \\
Lake Geneva & WI & 0 & 2 & 7651 & 43,205 & High & & 1.46 \\
Plymouth & MN & 0 & 2 & 70,576 & 84,392 & Low & X & 1.94 \\
Pontiac & MI & 0 & 1 & 59,515 & 27,528 & High & X & 77.80 \\
Saline & MI & 0 & 2 & 8810 & 63,958 & Low & & 5.86 \\
Southfield & MI & 0 & 2 & 71,739 & 49,841 & High & X & 79.17 \\
Springboro & OH & 0 & 2 & 17,409 & 96,094 & Low & X & -40.79 \\
Whitewater & WI & 0 & 3 & 14,390 & 29,784 & Low & & 23.57 \\
\hline
\end{tabular}

\subsection{Interviews and Coding}

Attempts were made to interview at least two officials in each city, at least one elected and one non-elected staff person, to get a more balanced perspective on the city's experience. Thirty-two interviews were conducted across the fifteen cities, including four mayors, twelve council members, eight city managers or city administrators, six economic development or community development directors, and two city planners. These semi-structured interviews were intended to last for $30 \mathrm{~min}$, but extended longer as necessary. Topics that were covered included the following: their city's financial and economic development concerns, what influenced the development of environmental and climate change-related efforts in the city, how other cities influenced their city, and efforts to learn about what other cities were doing and apply what they learned in their city. A more detailed list of example questions asked is included in Appendix B.

Following the interviews, the responses were coded based on issues relevant to financial challenges, economic development, and the influence that other cities have on them that emerged as consistent themes. This coding protocol included the following categories:

Financial and economic development considerations:

Concern Is the primary financial concern that the city has based on expenditures or revenue based on the interviews?

ED Change Did interviewees from the city describe a perceived need for innovative economic development strategies? ( $X$ denotes yes in Table 2 below.)

Built Out Did interviewees describe that their city had developed all available land? (X denotes yes in Table 2 below.) 
Table 2. Interview coding summary: City political economy and engagement with climate change.

\begin{tabular}{|c|c|c|c|c|c|c|}
\hline \multirow{2}{*}{ City Name } & \multicolumn{3}{|c|}{ Finances/Development } & \multicolumn{3}{|c|}{ Influence from Other Cities } \\
\hline & Concern & Built Out & ED Change & Research & Scope & Apply \\
\hline \multicolumn{7}{|c|}{ Cities Highly Engaged with Climate Change } \\
\hline Crystal & Expend. & $x$ & $x$ & Medium & National/Local & $x$ \\
\hline Edina & Expend. & $x$ & $x$ & High & National & $x$ \\
\hline Harper Woods & Rev. & $x$ & $x$ & Medium & State/National & $x$ \\
\hline Ithaca & Expend. & & $x$ & High & National/Inter. & $x$ \\
\hline Ludington & Expend. & $X$ & $x$ & Medium & State/Local & $x$ \\
\hline McHenry & Expend. & $x$ & & Low & Local/National & \\
\hline Monmouth & Expend. & & $X$ & High & Midwest/Inter. & $X$ \\
\hline \multicolumn{7}{|c|}{ Cities Not Engaging with Climate Change at All } \\
\hline Bryan & Rev. & & & Low & Local/State & \\
\hline Lake Geneva & Expend. & & & Low & Local & \\
\hline Plymouth & Rev. & & & Medium & Local & \\
\hline Pontiac & Rev. & $X$ & & Medium & Local & \\
\hline Saline & Rev. & & & Medium & Local/State & $x$ \\
\hline Southfield & Rev. & & & Low & Local & \\
\hline Springboro & Rev. & $X$ & & Low & Local & \\
\hline Whitewater & Rev. & & & Low & Local & \\
\hline
\end{tabular}

Influence from other cities:

Research The amount of research that interviewees described that their city did about other cities' policy efforts (coded as relatively low, medium, or high in Table 2 below).

Scope The scale where the other locations that these cities researched were located (coded as local (same metropolitan or micropolitan area), state, Midwest (region), national, or international in Table 2 below).

Apply Did the interviewees describe clear examples of successful application of policies that their city had learned about based on their research of other cities? (X denotes yes in Table 2 below.)

\subsection{Interview Results}

Differences between highly engaged cities and those not influenced by climate change considerations at all that arose in the discussions with these city officials are summarized in Table 2. When asked about financial challenges facing the city, highly engaged cities were more likely to emphasize controlling expenditures than acquiring (or losing) revenue (six of seven versus one of eight). Highly engaged cities were also more likely to describe that their community was entirely built out than cities who had no actions influenced by considerations about climate change (five out of seven versus one out of eight). One interviewee from a highly engaged city described how being built-out shaped their mindset in the following way, "being completely built-out and boxed-in, the focus now is on redevelopment, making the most out of what we already have."

Regarding economic development, highly engaged cities were more likely to describe that they had shifted their approach to economic development based on changing conditions (six out of seven versus zero out of eight). These shifts were associated with a perception that they needed to find innovative economic development strategies to respond to changing conditions. As an illustration, the following responses came from interviews in two rural cities with a higher-education institution; on the one hand, this first city was not associating policy efforts with climate change:

Respondent 1, “We have diversified (our economic development efforts) somewhat but we're not trying to move from column A to column B or anything like that per se-we're not walking away from our manufacturing base." 
Respondent 2, "The root problem is that for all the awareness, the community just doesn't grasp the importance (of altering economic development efforts). We're not very forward thinking."

On the other hand, the following respondent represented a second city that was highly engaged with climate change; their discussion of economic development explicitly ties together the city's past struggles dealing with global economic changes and their present motivation to reinvent themselves in order to remain competitive:

In most rural places, people look backwards, they want to return to the past ... but that doesn't work anymore ... In 1998, the predecessor to XXX here closed down. We really got knocked down because we weren't diversified and didn't have a strategy for something like that happening. How do we keep a major company like XXX here? How do we keep the college going and in town? Small colleges in the Midwest are really struggling and sometimes close down or relocate.

There were also distinctions related to how they engaged with the influence of other cities on their policy decisions. Highly engaged cities described more effort from those in city government regarding research on other cities, often stimulated by city council members. Out of the seven cities highly engaged with climate change, three cities described a relatively high level of research on other cities, three cities described a medium level, and one city described a low level. Among the eight cities that were not associating climate change with their policy actions, three cities described a relatively medium level of research on other cities, and five cities described a low level. Highly engaged cities with climate change were also more likely to describe examples of how the city had successfully applied what had been observed as well (six of seven versus one of eight). The contrast exhibited between the following two responses (both from city managers) were quite similar to those previously mentioned in this section, despite being from a different set of contrasting cities. The respondent from a city where no policy actions were influenced by climate change described a lack of interest in applying policies from other places in their government as, "I personally try to keep an idea about what is going on ... but [redacted] people love [redacted] and they won't look outside so it's really hard to get any traction on anything from outside." The respondent from a highly engaged city described a very different attitude about applying ideas from other cities, "plagiarism is a sin in academia, but it is a necessity for those working in cities. We steal each other's ideas all of the time.... You always end up copying from others and adapt their strategies."

Cities highly engaged with climate change were also influenced by cities at a broader geographic range. Six of the seven highly engaged cities described the influence of other cities nationally or internationally on their policy decisions, while cities whose policy actions were not being influenced by climate change only described the influence of other cities locally or at the state level. After a follow-up question, one respondent from a city whose policies were not influenced by climate change linked this locally focused perspective to the city's lack of desire to change, "We don't look much to other states or countries. I think we're missing out. We don't look to other places as much as I think we should. Why don't we? Our council got old and stale in the past. We got too comfortable as a city and those in the government were too comfortable too." In contrast, one of the respondents from a highly engaged city made a similar connection between the scope of their search and their city's desire to try new things, "we like being progressive, so, we look at what other progressive cities all over the country and even world are doing, especially Colorado recently." Cities highly engaged with climate change also appeared to be more likely to actually adapt the strategies that they saw being used in other places into their own policies as well. Six of the seven cities highly engaged with climate change gave examples of their city successfully applying strategies that they had learned about other cities using, while only one of the ones without climate change influencing a policy action did. 


\section{Regression Analysis}

\subsection{Model Development}

To more broadly explore the relationship between these factors and smaller cities' engagement with climate change policy, logistic regressions were performed. To differentiate between factors associated with high engagement with climate change mitigation versus adaptation, a dependent variable of high engagement (1) versus no engagement (0) was made for each. As above, high engagement was defined as being in the 75th percentile of those surveyed in terms of the number of policy actions they pursued that were influenced by climate change mitigation (six or more in this analysis) and climate change adaptation (three or more). There were 281 cities, with a population of 100,000 or less, that responded to the aforementioned survey; 72 cities $(26 \%)$ were highly engaged with climate change mitigation, 79 cities $(28 \%)$ were highly engaged with climate change adaptation, and 49 cities had to be removed from the logistic regression analysis because the necessary financial data could not be found. For the final mitigation logistic regression, 62 cities were highly engaged (1) and 135 were not engaged at all (0). For the final adaptation logistic regression, 70 cities were highly engaged (1) and 138 were not engaged at all (0).

Nine independent variables were included, based on the literature and interviews. The first three variables addressed financial conditions. In the interviews, those in highly engaged cities were more focused on expenditure-based challenges; therefore, it was hypothesized that experiencing an increase in expenditures would be associated with being highly engaged with mitigation and adaptation. A binary variable describing whether or not the city had experienced an increase in its expenditures from its 2006-2007 to 2009-2010 budgets was created based on available financial audits. The second was the city's unemployment rate (2010 five-year estimates from the American Community Survey), based on the hypothesis that existing economic strain (in this case, a higher unemployment rate) might push a city to engage with these relatively novel policy issues. A measure of the available financial resources in the city in the form of median household income was also included which had been negatively associated with engaging in climate change policy efforts [4,5].

Next, two variables addressed the theme of changing approaches to economic development from the interviews. The first was whether or not an individual was present in the city who was advocating for the city to change its approach to economic development, i.e., an economic policy entrepreneur, based on a survey described in a related study [51]. The second was changes in reliance on the manufacturing sector, i.e., the change in the percentage of residents employed in the manufacturing sector from the 2000 to 2010 American Community Surveys. According to the interviews, it was hypothesized that this variable would be negatively associated with high engagement because continued dependence on manufacturing might reflect a lack of willingness to pursue new economic development strategies.

The interviews also highlighted ways in which attention to the efforts of other cities and adoption of their ideas might influence engagement with climate change policy. Four independent variables were used to address the potential for a city to be influenced by others. The first was a variable that the interviews implied might be a catalyst of greater levels of research being done on other cities, i.e., the number of city council members. The more city council members that represent a city, the more possibilities there are for at least one to explore efforts in other places [51]. To consider the capacity for translating these ideas into action, a binary variable describing whether or not there was a committee in the city dedicated to environmental issues or sustainability was included. These smaller cities were unlikely to employ a staff person or department dedicated to environmental issues, therefore, committees represented arenas where people could bring ideas together and find ways to apply them towards environmental concerns. A binary variable describing whether the city was located in a metropolitan area (1) or not (0) was also included, as being located in a metropolitan region might lead smaller cities to perceive that they could "free ride" on the central city's actions and be less engaged with climate change policies [53]. Finally, a single binary variable described whether (1) or not (0) the 
city was participating in at least one of the following multi-city environmental networks: the Great Lakes St. Lawrence Cities Initiative, the ICLEI, the U.S. Conference of Mayors Climate Protection Agreement, or the UN's Compact of Mayors. Participation in any of networks was considered to be a binary indicator of the city's engagement with the policy actions of other cities at the national and international levels.

In order to account for other possible explanations of climate change policies in cities and avoid omitted variable bias, six other potential climate change policy drivers were included. The first policy driver was the city's population with the hypothesis that larger cities were more likely to engage with climate change policies [4]. The second policy driver was whether the city had a council-manager form of government or not because their perceived greater attention to efficiency might influence how cities would undertake climate change-related efforts [62]. A binary variable describing whether a climate change policy entrepreneur was present in the city or not was also used [51], as this advocates for climate change policies have been tied to cities' climate change actions $[4,5]$. The level of education attainment in the city has also been linked to the pursuit of climate change policies $[4,5,63]$, therefore, the city's bachelor's degree attainment rate was included. Finally, the number of natural disasters that a city had experienced was included because there was an assumed connection between natural disasters and the emergence of climate change policy action in cities [4,64]. Assessment of the impact of states on city actions was not a focus of this study, but the state that the city was in was included, to control for differences among the eight states.

\subsection{Regression Model Results}

Table 3 provides a summary of the results of the regression model assessing the factors underlying these smaller cities' high engagement with climate change mitigation and adaptation policy. Overall, the mitigation and adaptation models explained about $45 \%$ and $40 \%$ of the variation in the data, based on their adjusted R-squared values. The three financial conditions variables included (increased expenditures, unemployment, and median household income) were each positively associated with high engagement with mitigation $(p<0.05)$, but none were associated with adaptation.

Table 3. Logistic regression results: City high engagement with climate change.

\begin{tabular}{|c|c|c|c|c|}
\hline \multirow{2}{*}{ Variable } & \multicolumn{2}{|c|}{ Mitigation } & \multicolumn{2}{|c|}{ Adaptation } \\
\hline & Coeff. ${ }^{1}$ & SE & Coeff. $^{1}$ & SE \\
\hline \multicolumn{5}{|c|}{ Financial Drivers } \\
\hline Increased expenditures & 1.372 * & 0.62 & 0.412 & 0.49 \\
\hline Unemployment rate & $0.312 *$ & 0.15 & 0.171 & 0.12 \\
\hline Median household income & $0.546^{*}$ & 0.22 & 0.372 & 0.20 \\
\hline \multicolumn{5}{|c|}{ Economic change drivers } \\
\hline Econ dev entrepreneur & $1.406^{* *}$ & 0.47 & $1.766 * *$ & 0.46 \\
\hline Manufacturing change & 0.133 * & 0.07 & $0.114 *$ & 0.06 \\
\hline \multicolumn{5}{|c|}{ Influence from other cities' drivers } \\
\hline Council members & $0.225^{* *}$ & 0.07 & 0.080 & 0.07 \\
\hline Environmental commission & $1.395 *$ & 0.58 & $1.649 * *$ & 0.53 \\
\hline Metropolitan location & -0.586 & 0.60 & $-1.157 *$ & 0.53 \\
\hline Network participation & 1.056 & 0.66 & 1.018 & 0.68 \\
\hline \multicolumn{5}{|c|}{ Other climate change policy drivers } \\
\hline Population & -0.113 & 0.13 & -0.060 & 0.12 \\
\hline Council manager & 0.459 & 0.54 & 0.588 & 0.51 \\
\hline CC entrepreneur & 1.024 & 0.56 & 0.749 & 0.53 \\
\hline Bachelor's degree attainment & 0.002 & 0.02 & -0.005 & 0.02 \\
\hline Political partisanship & 0.014 & 0.01 & -0.001 & 0.01 \\
\hline Natural disasters & 0.102 & 0.12 & 0.139 & 0.12 \\
\hline
\end{tabular}


Table 3. Cont.

\begin{tabular}{|c|c|c|c|c|}
\hline \multirow{2}{*}{ Variable } & \multicolumn{2}{|c|}{ Mitigation } & \multicolumn{2}{|c|}{ Adaptation } \\
\hline & Coeff. $^{1}$ & SE & Coeff. $^{1}$ & SE \\
\hline \multicolumn{5}{|c|}{ States } \\
\hline \multicolumn{5}{|l|}{ Illinois (reference group) } \\
\hline Indiana & $3.118^{* *}$ & 1.11 & 1.301 & 0.904 \\
\hline Michigan & 1.756 & 0.93 & 0.118 & 0.818 \\
\hline Minnesota & 0.693 & 0.99 & -1.409 & 0.883 \\
\hline New York & 2.143 & 1.38 & 0.599 & 1.243 \\
\hline Ohio & $2.378 * *$ & 0.91 & -0.059 & 0.729 \\
\hline Pennsylvania & $4.130^{* *}$ & 1.41 & 1.320 & 1.146 \\
\hline Wisconsin & 1.645 & 0.97 & 0.131 & 0.743 \\
\hline Log likelihood & \multicolumn{2}{|c|}{-84.365} & \multicolumn{2}{|c|}{-97.738} \\
\hline Prob. > Chi-sq. & \multicolumn{2}{|c|}{0.000} & \multicolumn{2}{|c|}{0.000} \\
\hline Adjusted R-squared & \multicolumn{2}{|c|}{0.453} & \multicolumn{2}{|c|}{0.397} \\
\hline $\mathrm{N}^{\mathrm{I}}$ & \multicolumn{2}{|c|}{197} & \multicolumn{2}{|c|}{208} \\
\hline
\end{tabular}

Regarding the economic change variables, as expected based on the interviews, the presence of an economic development policy entrepreneur was positively associated with high engagement with climate change mitigation and adaptation $(p<0.01)$. However, contrary to expectations, the change in the percentage of those employed in the manufacturing sector was positively associated with high engagement with mitigation and adaptation $(p<0.05)$. There was also evidence that the factors examining the potential for a city to be influenced by others were associated with being highly engaged with climate change mitigation and adaptation. The presence of more council members was positively associated with high engagement with climate change mitigation $(p<0.01)$, but not adaptation. An environmental commission was positively associated with the city being highly engaged with climate change mitigation $(p<0.05)$ and adaptation $(p<0.01)$. Presence in a metropolitan area was negatively associated with high engagement with climate change adaptation $(p<0.05)$, but not with mitigation. There was no evidence for an association between participating in a larger multi-city network and high engagement with either climate change mitigation or adaptation. There was also no evidence found for such an association among high engagement and the other climate change policy drivers included in the model.

To better understand the extent to which shifts in the variables in this analysis translate into cities being more or less likely to be highly engaged with climate change mitigation or adaptation versus not being engaged with these issues at all, Table 4 provides a summary of predicted probabilities for the financial, economic development, and influence on other cities variables. In general, the average probability that a city in the model would be highly engaged with climate change mitigation was $31 \%$ and $34 \%$ for climate change adaptation. For each variable for both the mitigation and adaptation models, all values in the dataset were then set to a low value or a high value so that the resulting changes in the average probability that a city is highly engaged with either issue could be assessed. For the non-binary variables, the low value was the 10th percentile value of the cities in the analysis and the high value was the 90th percentile. Resulting probabilities from combinations of the financial, economic change, and influence variables were also included. For the mitigation model, changes related to altering median household income were the largest. Setting household income at $\$ 31,534$ (10th percentile) and $\$ 78,000$ (90th percentile) shifted the average probability that a city is highly engaged with mitigation from 0.20 to 0.53 . The next largest shift occurred from changes in the number of councilmembers which rose from 0.21 to 0.46 based on the number being 0 (10th percentile) versus 8 (90th percentile). For the adaptation model, the presence of an environmental commission had the most pronounced impact on the average probability, shifting it from 0.28 to 0.57 . The presence 
of an economic development entrepreneur had the second most pronounced impact, shifting the average probability from 0.17 to 0.43 . The combination of the financial drivers shifted the likelihood of mitigation high engagement more than adaptation ( 0.06 to 0.68 and 0.17 to 0.59 ) while the combination of economic change drivers shifted the likelihood of high engagement with adaptation slightly more than mitigation ( 0.12 to 0.51 and 0.13 to 0.46 ). The shifts related to the combined influence from other cities drivers was the same for the two models ( 0.14 to 0.82 and 0.18 to 0.86 ).

Table 4. Summary of predicted probabilities for likelihood of high engagement.

\begin{tabular}{|c|c|c|c|c|c|}
\hline \multirow{2}{*}{ Variables } & \multirow{2}{*}{ Based on } & \multicolumn{2}{|c|}{ Mitigation } & \multicolumn{2}{|c|}{ Adaptation } \\
\hline & & Low & High & Low & High \\
\hline \multicolumn{6}{|l|}{ Financial Drivers } \\
\hline Increased expenditures & 0 and 1 & 0.18 & 0.35 & 0.29 & 0.35 \\
\hline Unemployment rate & 10/90 Perc. & 0.23 & 0.41 & 0.28 & 0.39 \\
\hline Median household income & 10/90 Perc. & 0.20 & 0.53 & 0.25 & 0.51 \\
\hline Financial drivers combined & & 0.06 & 0.68 & 0.17 & 0.59 \\
\hline \multicolumn{6}{|c|}{ Economic Change Drivers } \\
\hline Econ dev entrepreneur & 0 or 1 & 0.19 & 0.38 & 0.17 & 0.43 \\
\hline Manufacturing change & 10/90 Perc. & 0.24 & 0.39 & 0.26 & 0.41 \\
\hline All economic change drivers & & 0.13 & 0.46 & 0.12 & 0.51 \\
\hline \multicolumn{6}{|c|}{ Influence from Other Cities Drivers } \\
\hline Council members & 10/90 Perc. & 0.21 & 0.46 & 0.29 & 0.39 \\
\hline Environmental commission & 0 or 1 & 0.27 & 0.49 & 0.28 & 0.57 \\
\hline Metropolitan location & 1 or 0 & 0.29 & 0.38 & 0.29 & 0.47 \\
\hline Network participation & 0 or 1 & 0.29 & 0.45 & 0.32 & 0.49 \\
\hline All influence drivers & & 0.14 & 0.82 & 0.18 & 0.86 \\
\hline Original probability & & \multicolumn{2}{|c|}{0.31} & \multicolumn{2}{|c|}{0.34} \\
\hline
\end{tabular}

\section{Discussion}

The results of these interviews and regression models help shed some light on how the logic of political economic rationalism shapes cities' considerations about engaging with climate change policy. According to the interviews, compared with cities where climate change was having no influence on policy actions, cities that were highly engaged with climate change were places that were more likely to be focused on managing expenditures than revenue and were compelled to pursue economic development innovations that would move the city beyond the industrial past of the rust belt region. This attitude was complemented by a greater interest in researching policy actions in other cities, a broader perspective on where such policy ideas might come from, and a greater likelihood of applying inspiration found in other contexts. Taken together, these findings point to a distinctive mindset amongst the highly engaged cities where their practical considerations about economic development and their cities' relationship to the world more broadly are already oriented towards change and innovation. This national or even international perspective is all the more remarkable given that these were all smaller cities with populations under 100,000. Climate change policy was something that was attached to this mindset and was something that was associated with being the kind of forward-thinking community that they aspired to be.

The results of the regression models provided additional support for this perceived connection between high engagement with climate change policy and financial pressures, economic development considerations, and the potential influence of other cities. Evidence was found that most of the variables used to assess these factors were associated with these cities being highly engaged with mitigation and adaptation in contrast to other climate change policy drivers. However, these results also further complicated the picture of exactly what differentiates small cities that are highly engaged with mitigation and adaptation versus those who were not engaging with these issues at all. The financial conditions in cities that were more likely to be highly engaged with climate change mitigation featured rising expenditures, higher unemployment, and higher median household incomes. Financially 
speaking then, experiencing financial pressures but still possessing economic wealth that could be mobilized in support of initiatives to address these challenges is a combination that makes it more likely that a smaller city will be highly engaged with mitigation. The results of the adaptation regression model did not provide support for a similar dynamic occurring surrounding climate change adaptation, meaning it is possible that, as of now, these cities more directly perceived that there was a possible connection between mitigation and financial gains than they perceived for adaptation.

For both the mitigation and adaptation models, high engagement was associated with both the presence of an economic development entrepreneur and a smaller change in manufacturing employment. The role of the presence of an economic development entrepreneur is consistent with the narrative about reinvention that emerged from the interviews, but the finding about manufacturing change provides an indication that the dynamic surrounding economic change and manufacturing employment is a complex one. In the interviews, there were examples where development demand afforded cities the ability to make developers fulfill their environmental and climate change goals. One interviewee explained, "so many people want to develop here right now that we don't worry about incentives. For us it's the opposite, the environmental work is something that developers give us in return for allowing them to have zoning approvals and follow through with their projects." On the one hand, similar to the association between high engagement with mitigation and adaptation and higher median household income, cities maintaining strong economic conditions in the form of manufacturing development might be able to more easily commit resources to climate change policies. On the other hand, a city's ability to retain more of its manufacturing employment might indicate the kind of proactive and innovative thinking related to economic development that would also drive them to pursue novel policy strategies such as climate change mitigation or adaptation. Deeper qualitative studies are needed to more carefully unpack the dynamic relationships among adjustments that cities are making to both economic and climate change-driven challenges.

The regression results related to the potential to be influenced by other cities were similarly supportive of the notion that having more opportunities for those in the city to pick up and potentially apply lessons from outside was associated with high engagement, but also pointed to the influence that cities have on one another being a more complex phenomenon for future research to unpack. For example, future research should assess the extent to which variables often associated with governance, such as the number of council members or the existence of departments or commissions, are impactful because they represent conduits for accessing and applying ideas from other places. However, future research should also look further into assessing the impact of the information-seeking behavior of individuals in a city that was described by the interviews. Unfortunately, the quantitative data available was not able to capture the behavioral aspects of cities bringing in ideas and adapting new policy actions based on the influence of others. Still, the observation that membership in the larger networks included in the regression was not associated with being highly engaged with climate change mitigation or adaptation underscores that these types of networks were not what the cities interviewed in this study meant when they described being influenced by other cities. (At the time of the interviews, two cities included in the analysis were members of transnational climate networks; Ithaca, New York was a member of ICLEI and the Compact of Mayors while Edina, MN was a member of ICLEI.) While there has been considerable attention given in the literature to how relationships between cities in international climate change policy networks influence climate change governance [65-67], the interviewees were describing the more typical, everyday ways in which cities constantly scope out what other comparable cities are doing to get a better sense of opportunities across a range of issues to better serve their residents. Attention to cities' more practical perceptions about peer cities that they already actively compare themselves to and learn from (rather than on global policy networks specialized for climate change policy) might be another opportunity to explore and better understand the everyday experience of pursuing climate change policy [7].

The ways in which practitioners' relatively informal peer networks, such as these, mix together guidance about pursuing novel new policy initiatives like climate change and more mundane shared 
concerns about resources and strategies can make these networks a particularly rich source of guidance on how climate change relates to their work [68]. The adoption of new climate change interventions amongst the more innovative members of cities' local peer networks might help to demonstrate the viability and utility of these policies, encouraging other cities in these local peer networks who are more likely to act as followers or laggards to ultimately adopt these innovations themselves [69]. The specific character of individual city's peer networks might also shape how cities determine strategies for tailoring specific policy actions to suit their own particular needs [68], providing insight into the learning and adaptive aspects of the diffusion process associated with climate change policy [14]. Future research should attend more to these kinds of everyday connections, particularly among smaller cities like these, as potential key bridges between the most exceptional, innovative global frontrunners and the vast majority of cities. While the cities whose policy actions did not include considerations about climate change reported a relatively lower interest in policy efforts in other cities, they did still pay attention to what other cities in their immediate area were doing and could be influenced by their actions. In this analysis, the highly engaged cities represented $25 \%$ or more of the cities studied. Following Rogers' [70] (p. 281) categorization of the process of innovation adoption, the highly engaged cities in this study would begin representing an emerging "early majority" of cities adopting climate change into their policy considerations. Their experiences are the ones that will create the momentum that will drive even less-likely cities to adopt these initiatives [70] (p. 284), especially if their experiences demonstrate that climate change policy can, in fact, help them address the kinds of financial or economic development concerns that they share with other smaller cities in their area that pay attention to them. However, differences between the highly engaged cities and those not engaged at all from the interviews and regression analyses provide some indications that the financial and economic contexts might be different between this early majority and the remaining potential late majority and laggard cities [70] (p. 284), representing a potential barrier to such a transition occurring. More attention to this early majority and how it grapples with climate change alongside its other everyday concerns is therefore needed to help those interested in the diffusion of climate change policy better understand how these policies are (and are not) adapted and evolve as they transition from innovative experiments into the everyday actions of an increasing majority of cities.

\section{Conclusions}

This study used 32 interviews and over 200 survey responses to explore ways in which the logic of political economic rationalism shapes whether or not smaller cities are highly engaged with climate change policy. The interviews compared responses about financial concerns, economic development considerations, and the influence of other cities, from officials in cities highly engaged with climate change policy and those where climate change did not influence their policy actions at all. A distinctive mindset amongst the highly engaged cities emerged from the interviews, defined by a desire to move beyond the industrial past of the region through economic development innovation informed by a greater interest in researching policy actions undertaken in other cities, a wide geographic perspective from which they could draw these new ideas from, and a high likelihood of actually adopting policies seen elsewhere in their own city. Then, two logistic regression analyses were conducted to gain a broader perspective of the extent to which factors associated with financial concerns, economic development considerations, and the potential influence of other cities were associated with cities either being highly engaged with climate change mitigation or adaptation versus not engaging at all. These results provided some support for the notion that these factors can help to explain the pursuit of climate change policy in cities and some insight into how such considerations are shaping decisions. However, they also emphasized that the dynamics between climate change policy and these factors were complex and that more qualitative research will need to be done to more effectively unpack the relationships involved [3]. Furthermore, this study's attention to smaller cities whose engagement with climate change policy is currently under researched, highlights that an early majority of cities may be playing a key role in shaping how climate change policy is being adapted to meet the 
more everyday financial and economic concerns of cities [7] as it diffuses into the majority of them. But the differences that this study also identified between these highly engaged cities and those not engaging with climate change policy at all, also emphasized that the politics surrounding adoption of these efforts would likely continue to shift in the move from this emerging early majority towards a growing majority. The role of the logics surrounding the financial concerns, economic development considerations, and influence from other cities explored in this paper are an essential but complex aspect of the pursuit of climate change policy in cities. Future research should continue to focus on these issues as cities all over the world continue to adapt and respond to a changing climate, a changing economy, and each other.

Funding: This research received no external funding.

Acknowledgments: The author would like to thank the editors and staff of the journal Atmosphere, as well as the anonymous reviewers for this article who offered a great deal of time, expertise, and insight that greatly enhanced the content presented here.

Conflicts of Interest: The authors declare no conflict of interest.

\section{Appendix A Sixteen Policy Actions}

- Measures to increase pedestrian transportation

- Enhanced parks

- Reduced energy use

- Increased building efficiency

- Altered stormwater management

- Promoted reuse of brownfields

- Increased tree canopy

- Altered wastewater management

- Promoted greater development density

- Made changes to fleet vehicles

- Enhanced public transportation options

- Altered building codes

- Altered emergency management strategy

- Developed alternative energy on buildings

- Developed water recycling or reuse

- Developed alternative energy options

\section{Appendix B Example Interview Questions}

- What are the most important challenges currently facing your city concerning the city's budget and finances?

- What are the most important challenges currently facing your city concerning growth and economic development?

- What (or who) has shaped the development of "environmental" work in your city over time? Follow up questions about climate change specifically were added as necessary.

- How do other cities influence policies undertaken in your own city? Can you give me any specific examples?

- Why is it important for you to understand the work that is going on in other cities?

- What other cities do you think about when making decisions about your own work? Where are they located?

- How do you learn about what these other cities are doing? 


\section{References}

1. Bulkeley, H. Cities and the Governing of Climate Change. Annu. Rev. Environ. Resour. 2010, 35, $229-253$. [CrossRef]

2. Broto, V.C.; Bulkeley, H. A survey of urban climate change experiments in 100 cities. Glob. Environ. Chang. 2013, 23, 92-102. [CrossRef]

3. van der Heijden, J. Studying urban climate governance: Where to begin, what to look for, and how to make a meaningful contribution to scholarship and practice. Earth Syst. Gov. 2019, 1, 100005. [CrossRef]

4. Krause, R.M. Policy Innovation, Intergovernmental Relations, and the Adoption of Climate Protection Initiatives by U.S. Cities. J. Urban Aff. 2011, 33, 45-60. [CrossRef]

5. Krause, R.M. Political Decision-Making and the Local Provision of Public Goods: The Case of Municipal Climate Protection in the US. Urban Stud. 2012, 49, 2399-2417. [CrossRef]

6. Yeganeh, A.J.; McCoy, A.P.; Schenk, T. Determinants of climate change policy adoption: A meta-analysis. Urban Clim. 2020, 31, 100547. [CrossRef]

7. Broto, V.C.; Westman, L.K. Ten years after Copenhagen: Reimagining climate change governance in urban areas. WIREs Clim. Chang. 2020, 11, e643.

8. Bulkeley, H.; Stripple, J. Conclusion: Towards a Critical Science of Climate Change? In Governing the Climate: New Approaches to Rationality, Power and Politics; Stripple, J., Bulkeley, H., Eds.; Cambridge University Press: Cambridge, UK, 2013; pp. 243-260.

9. Okereke, C.; Bulkeley, H.; Shroeder, H. Conceptualizing Climate Governance beyond the International Regime. Glob. Environ. Politics 2009, 9, 58-78. [CrossRef]

10. van der Heijden, J. From leaders to majority: A frontrunner paradox in built-environment climate governance experimentation? J. Environ. Plan. Manag. 2018, 61, 1383-1401. [CrossRef]

11. van der Heijden, J. Innovations in Urban Climate Governance: Voluntary Programs for Low Carbon Buildings and Cities; Cambridge University Press: Cambridge, UK, 2017.

12. Kalafatis, S.E. Colleagues, Competitors, Creators: City Governance among Peers and Its Implications for Addressing Climate Change. Ph.D. Dissertation, University of Michigan, Ann Arbor, MI, USA, 2016.

13. Hodson, M.; Marvin, S. 'Urban Ecological Security': A New Urban Paradigm? Int. J. Urban Reg. Res. 2009, 33, 1468-2427. [CrossRef]

14. van der Heijden, J. Understanding voluntary program performance: Introducing the diffusion network perspective. Regul. Gov. 2020, 14, 44-62. [CrossRef]

15. High, S. Industrial Sunset: The Making of North America's Rust Belt, 1969-1984; University of Toronto Press: Toronto, ON, Canada, 2003; ISBN 978-0802085283.

16. Longworth, R.C. Caught in the Middle: America's Heartland in the Age of Globalism; Bloomsbury: New York, NY, USA, 2009.

17. Pryor, S.C.; Scavia, D.; Downer, C.; Gaden, M.; Iverson, L.; Nordstrom, R.; Patz, J.; Robertson, G.P. Ch. 18: Midwest. In Climate Change Impacts in the United States: The Third National Climate Assessment; Melillo, J.M., Richmond, T.C., Yohe, G.W., Eds.; U.S. Global Change Research Program: Washington, DC, USA, 2014; pp. $418-440$.

18. Baule, W.; Gibbons, E.; Briley, L.; Brown, D. Synthesis of the Third National Climate Assessment for the Great Lakes Region; Integrated Sciences + Assessments: Great Lakes, MI, USA, 2014.

19. Kalafatis, S.E.; Campbell, M.; Fathers, F.; Laurent, K.L.; Friedman, K.B.; Krantzberg, G.; Scavia, D.; Creed, I.F. Out of control: How we failed to adapt and suffered the consequences. J. Great Lakes Res. 2015, 41, $20-29$. [CrossRef]

20. Walters, W. Governmentality: Critical Encounters; Routledge: New York, NY, USA, 2012.

21. Tiebout, C.M. A Pure Theory of Local Expenditures. J. Political Econ. 1956, 64, 416-424. [CrossRef]

22. Ostrom, V.; Tiebout, C.M.; Warren, R. The Organization of Government in Metropolitan Areas: A Theoretical Inquiry. Am. Political Sci. Rev. 1961, 55, 831-842. [CrossRef]

23. Schneider, M. The Competitive City: The Political Economy of Suburbia; University of Pittsburgh Press: Pittsburgh, PA, USA, 1989.

24. Wolman, H.; Spitzley, D. The Politics of Local Economic Development. Econ. Dev. Q. 1996, 10, 115-150. [CrossRef]

25. Peterson, P.E. City Limits; University of Chicago Press: Chicago, IL, USA, 1981. 
26. Eberts, R.W.; Gronberg, T.J. Jurisdictional Homogeneity and the Tiebout Hypothesis. J. Urban Econ. 1981, 10, 227-239. [CrossRef]

27. Hamilton, B.W. Zoning and property taxation in a system of local governments. Urban Stud. 1975, 12, $205-211$. [CrossRef]

28. Pack, H.; Pack, J.R. Metropolitan Fragmentation and Suburban Homogeneity. Urban Stud. 1977, 14, $191-201$. [CrossRef]

29. Massey, D.S.; Denton, N.A. American Apartheid: Segregation and the Making of the Underclass; Harvard University Press: Cambridge, MA, USA, 1993.

30. Epple, D.; Zelenitz, A. The Implications of Competition Among Jurisdictions: Does Tiebout Need Politics? J. Political Econ. 1981, 89, 1197-1217. [CrossRef]

31. Sjoquist, D.L. The Effect of the Number of Local Governments on Central City Expenditures. Natl. Tax J. 1982, 35, 79-87.

32. Teske, P.; Schneider, M.; Mintrom, M.; Best, S. Establishing the micro foundations of a macro theory: Information, movers, and the comparative local market for public goods. Am. Political Sci. Rev. 1993, 87, 702-713. [CrossRef]

33. Basolo, V.; Lowery, D. Delineating the Regional Market in Studies of Inter-City Competition. Urban Geogr. 2010, 31, 369-384. [CrossRef]

34. Braun, E. City Marketing: Towards an integrated approach. Ph.D. Dissertation, Erasmus University, Rotterdam, The Netherlands, 2008.

35. Kavaratzis, M.; Hatch, M.J. The dynamics of place brands: An identity-based approach to place branding theory. Mark. Theory 2013, 13, 69-86. [CrossRef]

36. Florida, R. The Rise of the Creative Class: And How It's Transforming Work, Leisure, Community and Everyday Life; Basic Books: New York, NY, USA, 2002.

37. Hospers, G.-J. Creative cities: Breeding places in the knowledge economy. Knowl. Technol. Policy 2003, 16, 143-162. [CrossRef]

38. Lucarelli, A.; Berg, P.O. City branding: A state-of-the-art review of the research domain. J. Place Manag. Dev. 2011, 4, 9-27. [CrossRef]

39. Anttiroiko, A.-V. City Branding as a Response to Global Intercity Competition. Growth Chang. 2015, 46, 233-252. [CrossRef]

40. Heinrichs, D.; Krellenberg, K.; Fragkias, M. Urban responses to climate change: Theories and governance practice in cities of the Global South. Int. J. Urban Reg. Res. 2013, 37, 1865-1878. [CrossRef]

41. Aggarwal, R.M. Strategic Bundling of Development Policies with Adaptation: An Examination of Delhi's Climate Change Action Plan. Int. J. Urban Reg. Res. 2013, 37, 1902-1915. [CrossRef]

42. Metz, B.; Davidson, O.; Swart, R.; Pan, J. Intergovernmental Panel on Climate Change (IPCC) Third Assessment Report. Climate Change 2001: Mitigation; Cambridge University Press: Cambridge, MA, USA, 2001.

43. Denton, F.; Wilbanks, T.J.; Abeysinghe, A.C.; Burton, I.; Gao, Q.; Lemos, M.C.; Masui, T.; O’Brien, K.L.; Warner, K. Climate-resilient pathways: Adaptation, mitigation, and sustainable development. In Climate Change. 2014: Impacts, Adaptation, and Vulnerability. Part A: Global and Sectoral Aspects. Contribution of Working Group II to the Fifth Assessment Report of the Intergovernmental Panel on Climate Change; Cambridge University Press: New York, NY, USA, 2014; pp. 1101-1131.

44. Kalafatis, S.E. Identifying the Potential for Climate Compatible Development Efforts and the Missing Links. Sustainability 2017, 9, 1642. [CrossRef]

45. Kalafatis, S.E. When Do Climate Change, Sustainability, and Economic Development Considerations Overlap in Cities? Environ. Politics 2018, 27, 115-138. [CrossRef]

46. Kalafatis, S.E. Comparing Climate Change Policy Adoption and Its Extension across Areas of City Policymaking. Policy Stud. J. 2018, 46, 700-719. [CrossRef]

47. Kousky, C.; Schneider, S.H. Global climate policy: Will cities lead the way? Clim. Policy 2003, 3, 359-372. [CrossRef]

48. Bulkeley, H.; Kern, K. Local government and the governing of climate change in Germany and the UK. Urban Stud. 2006, 43, 2237-2259. [CrossRef]

49. Jeffers, J.M. Double exposures and decision making: Adaptation policy and planning in Ireland's coastal cities during a boom-bust cycle. Environ. Plan. A 2013, 45, 1436-1454. [CrossRef] 
50. Cashmore, M.; Wejs, A. Constructing legitimacy for climate change planning: A study of local government in Denmark. Glob. Environ. Chang. 2014, 24, 203-212. [CrossRef]

51. Kalafatis, S.E.; Lemos, M.C. The emergence of climate change policy entrepreneurs in urban regions. Reg. Environ. Chang. 2017, 17, 1791-1799. [CrossRef]

52. Hendrick, R.; Shi, Y. Macro-Level Determinants of Local Government Interaction: How Metropolitan Regions in the United States Compare. Urban Aff. Rev. 2015, 51, 414-438. [CrossRef]

53. Sharp, E.B.; Daley, D.M.; Lynch, M.S. Understanding Local Adoption and Implementation of Climate Change Mitigation Policy. Urban Aff. Rev. 2011, 47, 433-457. [CrossRef]

54. Tanner, T.; Mitchell, T.; Polack, E.; Guenther, B. Urban Governance for Adaptation: Assessing Climate Change Resilience in Ten Asian Cities. IDS Work. Pap. 2009, 315, 1-47. [CrossRef]

55. Anguelovski, I.; Carmin, J. Something borrowed, everything new: Innovation and institutionalization in urban climate governance. Curr. Opin. Environ. Sustain. 2011, 3, 1-7. [CrossRef]

56. Delman, J. Climate change politics and Hangzhou's 'green city making'. In Branding Chinese Megacities; Berg, P.O., Björner, E., Eds.; Edward Elgar Publishing: Cheltenham, UK, 2014; pp. 249-261.

57. Ooi, C.-S. Paradoxes of City Branding and Societal Challenges. In City Branding: Theory and Cases; Dinnie, K., Ed.; Palgrave Macmillan: Houndsmills, UK, 2011; pp. 54-61.

58. Boyne, G.A.; Gould-Williams, J.S.; Law, J.; Walker, R.M. Explaining the adoption of innovation: An empirical analysis of public management reform. Environ. Plan. C Gov. Policy 2005, 23, 419-435. [CrossRef]

59. Damanpour, F.; Schneider, M. Characteristics of Innovation and Innovation Adoption in Public Organizations: Assessing the Role of Managers. J. Public Adm. Res. Theory 2009, 19, 495-522. [CrossRef]

60. Nelson, K.L.; Svara, J.H. Form of Government Still Matters: Fostering Innovation in U.S. Municipal Governments. Am. Rev. Public Adm. 2012, 42, 257-281. [CrossRef]

61. Marquart-Pyatt, S.T.; McCright, A.M.; Dietz, T.; Dunlap, R.E. Politics eclipses climate extremes for climate change perceptions. Glob. Environ. Chang. 2014, 29, 246-257. [CrossRef]

62. Bae, J.; Feiock, R. Forms of Government and Climate Change Policies in US Cities. Urban Stud. 2013, 50, 1-13. [CrossRef]

63. Krause, R.M. An Assessment of the Impact That Participation in Local Climate Networks Has on Cities' Implementation of Climate, Energy, and Transportation Policies. Rev. Policy Res. 2012, 29, 585-604. [CrossRef]

64. Zahran, S.; Brody, S.D.; Vedlitz, A.; Grover, H.; Miller, C. Vulnerability and Capacity: Explaining Local Commitment to Climate-Change Policy. Environ. Plan. C Gov. Policy 2008, 26, 544-562. [CrossRef]

65. Lee, T. Global Cities and Climate Change: Translocal Relations of Environmental Governance; Routledge: New York, NY, USA, 2014.

66. Lee, T.; Jung, H.A. Mapping city-to-city networks for climate change action: Geographic bases, link modalities, functions, and activity. J. Clean. Prod. 2018, 182, 96-104. [CrossRef]

67. Davidson, K.; Coenen, L.; Acuto, M.; Gleeson, B. Reconfiguring urban governance in an age of rising city networks: A research agenda. Urban Stud. 2019, 56, 3540-3555. [CrossRef]

68. Kalafatis, S.E.; Lemos, M.C.; Lo, Y.-J.; Frank, K.A. Increasing information usability for climate adaptation: The role of knowledge networks and communities of practice. Glob. Environ. Chang. 2015, 32, 30-39. [CrossRef]

69. Kern, K. Cities as leaders in EU multilevel climate governance: Embedded upscaling of local experiments in Europe. Environ. Politics 2019, 28, 125-145. [CrossRef]

70. Rogers, E.M. Diffusion of Innovations, 5th ed.; Free Press: New York, NY, USA, 2003.

Publisher's Note: MDPI stays neutral with regard to jurisdictional claims in published maps and institutional affiliations.

(C) 2020 by the author. Licensee MDPI, Basel, Switzerland. This article is an open access article distributed under the terms and conditions of the Creative Commons Attribution (CC BY) license (http://creativecommons.org/licenses/by/4.0/). 